\title{
IDENTIFYING BREEDING HABITAT FOR THE IBERIAN LYNX: INFERENCES FROM A FINE-SCALE SPATIAL ANALYSIS
}

\author{
Néstor Fernández, ${ }^{1,3}$ Miguel Delibes, ${ }^{1}$ Francisco Palomares, ${ }^{1}$ And David J. MladenofF ${ }^{2}$ \\ ${ }^{1}$ Department of Applied Biology, Estación Biológica de Doñana, CSIC, Avda. María Luisa s/n 41013 Seville, Spain \\ ${ }^{2}$ Department of Forest Ecology and Management, University of Wisconsin-Madison, Madison, Wisconsin 53706-1598 USA
}

Abstract. Empirical landscape habitat models are valuable tools for addressing species conservation issues in heterogeneous landscapes. These have been particularly useful for animal populations requiring extensive areas, like large mammalian carnivores. Although models are scale-dependent, they are often based exclusively on coarse-grained information on landscape structure and species distribution. However, accurate discrimination and quality assessment of breeding habitats may require more detailed information on both individuals' habitat use and landscape patterns.

Here, we modeled breeding habitat for the Iberian lynx (Lynx pardinus), an endangered specialist of Mediterranean native ecosystems, in a human-dominated landscape. For this, we used radiotelemetry data on breeding individuals and fine-grained landscape variables obtained over an areal extent encompassing an entire lynx metapopulation. In addition, we restricted the study domain to areas of potential presence within this extent based on previous habitat analyses. This fine-scale landscape analysis and design aimed to test whether it was possible to obtain detailed inferences on breeding habitat distribution and quality within more coarsely defined habitats that only indicate where the species can be found. Landscape composition factors (i.e., fine-grain variables of landscape pattern within territories) and context factors (variables on geographical location of territories) were combined in different candidate habitat models. These reflected various hypotheses involving territory presence and size, including vegetation structure characteristics, landscape heterogeneity and complexity, favorable prey habitat, and human disturbance. The best approximating model for territory presence included only one landscape composition variable, namely, density of ecotones between scrubland and pastureland, which favored presence. For this model, classification accuracy was $>80 \%$ in $94 \%$ of cross-validation tests performed. The best approximating model for territory size explained $65 \%$ of the variation in size and included also density of ecotones, plus mean coverage of tall shrubs within territories; both correlated negatively with size. We show how these predictors are also related to prey density and suggest that this low-hierarchical-level relationship between the prey and patterns of the landscape can be interpreted as a likely mechanism explaining breeding habitat distribution and quality at a higher level. Our approach shows the potential of finescale landscape analysis to understand patterns of breeder abundance, and to better manage population viability of threatened species in human-populated areas.

Key words: breeding habitat quality; carnivores; conservation biology; Doñana; endangered species; habitat modeling; habitat restoration; landscape ecology; Lynx pardinus; Oryctolagus cuniculus; territory size.

\section{INTRODUCTION}

The identification of factors affecting the distribution and abundance of animals is a traditional key matter of ecology, closely related to the study of habitat preferences of organisms (e.g., Southwood 1977, Johnson 1980). This topic has acquired added relevance in the field of conservation biology, since characterizing species' habitats is essential to address the effects of habitat loss, degradation, and fragmentation on species' risk of extinction (Myers 1997), and for planning habitat restoration (MacMahon 1997).

Manuscript received 6 March 2002; revised 10 December 2002; accepted 14 January 2003; final version received 18 February 2003. Corresponding Editor: D. B. Lindenmayer.

${ }^{3}$ E-mail: nestor@ebd.csic.es
More recently, landscape ecology has provided a theoretical framework for interpreting interactions between organisms and environment in an explicit context of spatial heterogeneity (Wiens et al. 1993, Pickett and Cadenasso 1995, Lima and Zollner 1996). Recognition of landscapes from a species-centered perspective has greatly contributed to the study of organism distributions, providing more realistic scenarios in which to assess risks associated with landscape alteration. In addition, analytical tools like geographic information systems, landscape pattern indices, etc., have allowed extensive application of this approach for a wide variety of management problems, including the design of species-specific conservation strategies from a landscape perspective (e.g., Haslett 1990, Maehr and Cox 1995, Pearson et al. 1999, Turner et al. 2001). 
Following these theoretical and methodological advances, empirical models of a variety of forms (probabilistic functions, qualitative rules, etc.) are increasingly being adapted for evaluating likelihoods of species' occurrence in a spatially explicit context. These models are commonly based on the association of species' presence-absence data with quantitative patterns of landscapes; their outcomes interpreted in terms of habitat suitability (Buckland and Elston 1993, Boyce and McDonald 1999). Their utility has been particularly emphasized to investigate conservation problems of animals highly sensible to habitat alteration and with large spatial requirements, like mammalian carnivores (Carroll et al. 2001). Landscapes needed for population persistence of these species frequently comprise lowhumanized habitat patches extending over large areas. Therefore, the challenge of preserving carnivore habitats requires integrative ecosystem management at broad spatial scales (e.g., Wikramanayake et al. 1998, Mladenoff et al. 1999, Merrill et al. 1999, Carroll et al. 2001). A special interest in habitat studies oriented to carnivore conservation exists also for their potential utility in preserving many other species of the same ecosystems but with lower area requirements (Noss et al. 1996).

However, habitat models commonly identify habitats as areas with various probabilities of finding individuals of a species, without consideration of demographic processes occurring within them (e.g., Massolo and Meriggi 1998, Carroll et al. 1999). Instead, many questions of population ecology and conservation require clear discrimination between habitats suitable for breeding and nonbreeding areas where animals may be found, even with a high probability (Gustafson and Gardner 1996, Tyre et al. 2001). To address this, there is a need to discriminate areas used by breeding individuals over the range of landscapes being studied; information scarcely available for elusive species like mammalian carnivores.

Moreover, it may be equally important to recognize heterogeneities affecting breeding habitat quality within these areas; that is, variations in habitat characteristics that influence parameters of population productivity like number of breeding females per area unit, number of offspring per female, etc. Spatial variation in quality of breeding habitats is of primary contemporary concern for our understanding of population dynamics and persistence in landscapes (Murphy et al. 1990, Franklin et al. 2000). Research on habitat modeling oriented to species conservation needs to advance in this respect.

Spatial habitat inferences largely depend on a prior selection of the scale of landscape analysis, which is defined by the spatial extent of the study domain and the grain of the information used to identify patches within this extent (King 1997). We suggest that assessment of breeding habitats and their quality may benefit from fine-scale landscape analyses within areas of the species' potential presence. For example, restricting the study domain to vegetation formations where the focal species is likely to be found can provide more precise inferences on its breeding habitat than if the extent is exclusively defined by administrative or other arbitrary boundaries. With respect to grain, the need for environmental information over large areas usually limits habitat modeling for mammalian carnivores and other species to make use of coarse-grained variables, such as relative area of a given coarsely defined forest type, density of human infrastructure and even photogrammetric measurements of ecosystem functions like vegetation greenness (Corsi et al. 1999, Mace et al. 1999, Schadt et al. 2002). Arguably, finergrain landscape information may also help to identify habitat more accurately if the animal responds to some landscape attributes not evident using such coarsegrained information. From an applied perspective, finescaled landscape models can benefit conservation of endangered species by providing habitat management solutions not afforded by coarser scale approaches.

The next logical step should be understanding links between landscape patterns and species-specific resource requirements. This step is needed to provide causal insights into the habitat selection process, a goal difficult to address from the sole application of statistical models (Boyce and McDonald 1999, Cumming 2000). Abundance of food is a prime factor determining habitat selection by animals, which also influences female reproductive rates and breeder density (Newton 1998, Boutin 1990); therefore, it seems useful to explore relationships between landscape patterns and access to food for improving inferences on habitat distribution and quality on landscapes.

This study addresses breeding habitat evaluation for an endangered mammalian carnivore, the Iberian lynx (Lynx pardinus), over the Doñana region in southwestern Spain. For this, we analyzed fine-grained information on landscape characteristics within previously defined habitats where lynx individuals were found. Here, we use the term "breeding habitat" to mean conditions present in an area that allow reproduction of a given organism, although other authors have denoted this simply as "habitat" (Hall et al. 1997). We also differentiate gradients of habitat quality for breeding in terms of landscape capacity to support different densities of breeders. The following questions are addressed. (1) Can the distribution of Iberian lynx breeding territories be related to fine-scale landscape patterns within broadly identified habitats? (2) Can variations in quality of breeding habitats be predicted from similar fine-scale analyses? (We use the breeding territory size as an index of breeding habitat quality, relying on the principle that many animals, and the Iberian lynx in particular, adjust their territories to the minimum functional space possible in relation to resource availability; Ferreras et al. 1997, Sherman and Eason 1998 and references cited therein.) (3) Given 


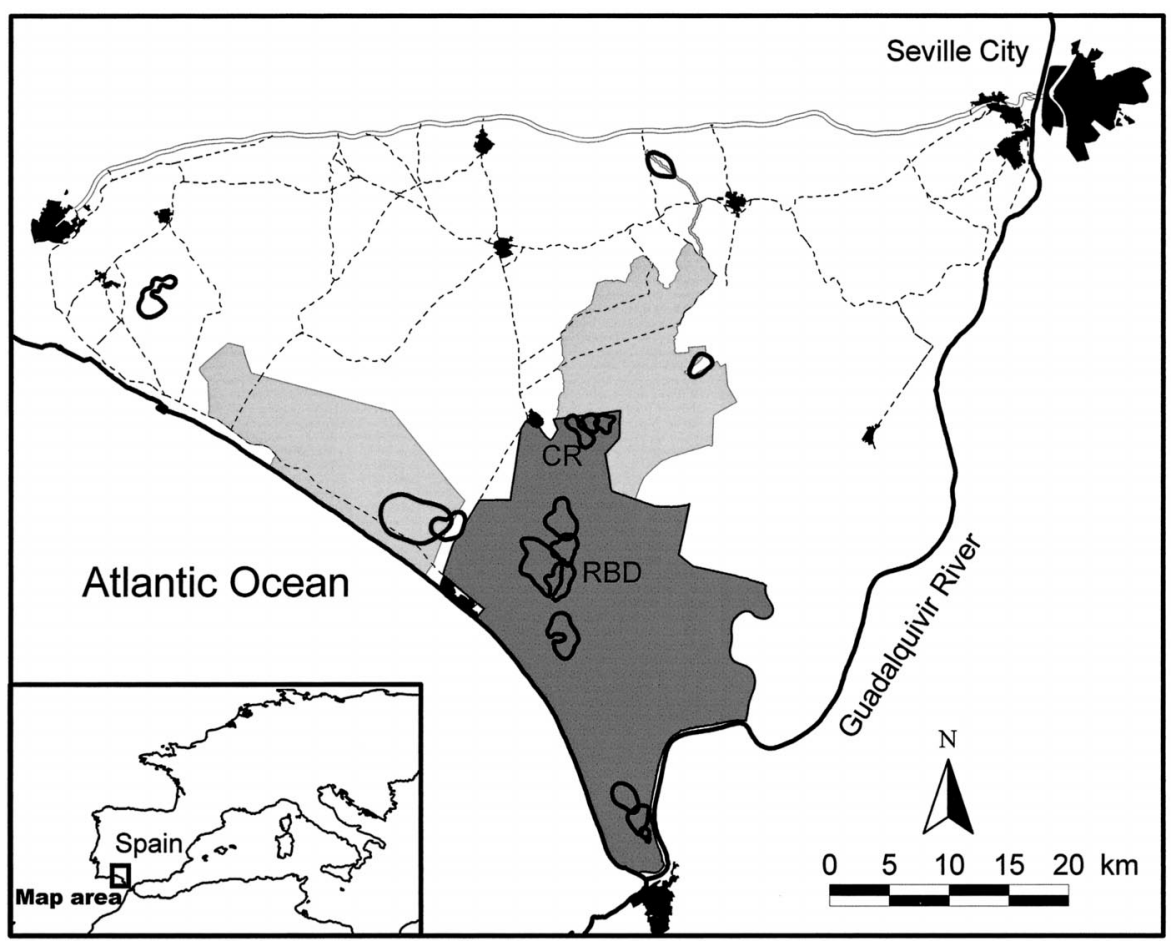

FIG. 1. The Doñana area, in southern Spain. The dark gray area represents the Doñana National Park, and the light gray areas represent the sectors north and west of Doñana Natural Park. Cities and mayor towns are in black. A highway represented with double line bounds the Doñana area to the north. Other roads are represented as dashed lines, and the Guadalquivir River as a continuous line. Black outlined polygons show Iberian lynx territories.

that food is a prime factor determining habitat selection by animals and foraging theory has been suggested to be the ultimate explanation of habitat probabilistic functions (Boyce and McDonald 1999), does any association exist between the fine-scale landscape predictors of breeding habitat for the Iberian lynx, and the abundance of its primary prey?

The Iberian lynx is a medium-sized mammalian carnivore endemic to the southwestern Iberian Peninsula. Only nine isolated metapopulations of the species persisted in the late 1980s, eight of them composed of fewer than 60 individuals (Rodríguez and Delibes 1992). There is evidence indicating decreasing trends in these populations since then (Delibes et al. 2000). The decline of Iberian lynx populations during the last century is believed mainly due to human changes in land uses, which have caused reduction and fragmentation of the native Mediterranean ecosystems on which the lynx depends. The species is currently classified as the most endangered feline in the world (Nowell and Jackson 1996). It is also considered the most endangered mammalian carnivore in Europe, of priority attention in the European Union plans for the conservation of biodiversity (Delibes et al. 2000). In Doñana, a metapopulation of Iberian lynx persists under serious human pressures that come mainly from habitat destruction for agricultural and urban development, and direct human-induced mortality (Ferreras et al. 1992).
Nowadays, a prime factor on which the survival of the Iberian lynx in Doñana depends is the preservation and improvement of habitat for breeding, especially within the already protected natural areas (Gaona et al. 1998, Ferreras et al. 2001). Understanding the key landscape elements that correlate with habitat selection and quality can help to guide and streamline conservation efforts for population persistence of the Iberian lynx, as well as other species.

\section{Methods \\ Study area}

The study area comprised $\sim 870 \mathrm{~km}^{2}$ in southwestern Spain, most of it included within the Doñana National and Natural Parks (Fig. 1). It is a natural area limited by the Atlantic Ocean to the west, the Guadalquivir River to the east, and crops extending to the north several kilometers towards the Sierra Morena Mountains. The area is flat and mostly near sea level, with a top elevation of $106 \mathrm{~m}$; soils are predominantly sandy, from marine origin. Climate is Mediterranean subhumid and has marked seasons: winters are mild and wet, and summers are hot and dry. Mean annual precipitation is $600 \mathrm{~mm}$. Its situation between the Atlantic Ocean and Mediterranean Sea and in southern Europe influences the existence of some of the highest biological diversity in the continent, particularly of vertebrate 
animals and vascular plants (Fernández-Delgado 1997). Three ecosystem types are predominant: fixed dunes, mobile dunes and marshes. Vegetation in the fixed dunes is a mixture of different degradation stages of autochthonous Mediterranean shrubland (Castroviejo 1993). Many areas are dominated by plantations of pines (Pinus pinea) with variable understory vegetation. Shrubland is dominated by Halimium halimifolium and Ulex spp. or Erica spp. heaths depending on the depth of the water table. More mature shrubland areas with Pistacia lentiscus and Myrtus communis can be found mainly in the north. Some other areas are transformed with Eucalyptus camaldulensis plantations, introduced during the first half of the 20th century.

The Doñana National Park is fully protected and human access is regulated. Some traditional uses are maintained under the control of conservation authorities; they include some extensive cattle raising, apiculture, and fishing with traditional methods. The Doñana Natural Park is adjacent to the National Park as a buffer area, and has lower-level protection. Human use here is more intense, there is no restriction on access, and it is crossed by several roads and public ways. Uses include exploitation of natural resources such as pine seeds, cork bark, and hunting. Most lands surrounding the parks have been transformed for crops. Several towns are adjacent to or near both National and Natural Parks (Fig. 1). These surroundings support intense human activity, with an important agricultural and urban development, mining industries and hundreds of thousands of tourists visiting them each year (FernándezDelgado 1997).

\section{Species life history traits relevant for model design}

The Iberian lynx is a territorial species defending highly exclusive areas against conspecifics of the same sex. Only resident females seem able to reproduce, and breeding territories usually consist of areas shared between one adult male and one adult female, and also by their yearlings before they disperse. In Doñana, male home ranges usually overlap one single female, showing a mating system close to monogamy, and all residents maintain stable home ranges throughout the year. Territory acquisition occurs after vacancy or displacement of a resident individual, and the spatial arrangement of the new resident's home range have been shown to be highly coincident with the antecedent ones (Ferreras et al. 1997, Palomares et al. 2001). We used the breeding territory as sample unit to develop spatial models of Iberian lynx habitat.

\section{Territory data}

For identifying the territories, we analyzed a radiotelemetry database of 14009 locations from 46 individuals captured in Reserva Biológica (1983-1992) and Coto del Rey (1993-1997), where the two most important Iberian lynx subpopulations are found in
Doñana (Fig. 1; for details on tagging and radio-tracking procedures, see Palomares et al. 2000). We delimited the breeding territories using resident female home ranges. Residents were defined as adults ( $\geq 3 \mathrm{yr}$ old) maintaining site fidelity for at least 10 months. When enough radio-tracking data were not available to accurately estimate a female home range (i.e., <40 locations), resident male home ranges were used. All home ranges were estimated using the $80 \%$ fixed Kernel isoline (KE80; Seaman and Powell 1996), which defined territory boundaries satisfactorily and minimized overlap (Palomares et al. 2001). We could obtain confirmation of breeding events within most territories from direct observations and captures of kittens by scientific and technical personnel during various monitoring programs from 1.983 to 1.997 (N. Fernández, unpublished data).

\section{Variable derivation and spatial analyses}

Thirteen variables were selected to create candidate models of territory distribution and size. These were grouped into (1) composition variables, i.e., those based on the landscape structure within territories; and (2) context variables, which described the surrounding landscape where the territories were placed (Tables 1 and 2; see next section for arguments on variable selection). They were calculated from five vector digital map layers of data on landscape context and composition. A 1:50000 scale land use/land cover map for the year 1995 was obtained from the Sistema de Información Ambiental de Andalucía based on a combination of supervised and unsupervised classification of Landsat 5 TM images combined with interpretation of 1:60000 color aerial photographs (Moreira and Fernández-Palacios 1995). We reclassified the 112 land cover types contained in this map into 10 units: urban land, continental water bodies and marsh, crops, dunes, eucalyptus plantations, pine forests, dense Mediterranean shrubland, dispersed shrubland, mixed pastureland, and pastureland. Given that the grain of the land use/land cover map was too coarse for the purposes of this study and contained poor information about the structure of the vegetation, we built a specific fine-scale map of the structure of the vegetation. For this, we used 1:15000 color-infrared aerial photographs of Doñana National and Natural Parks dated 12 June 1998. The fine-scale vegetation map was interpreted outside the areas covered by coarse land cover units known to be avoided by either predispersal or postdispersal individuals (Palomares et al. 2000). These were urban land, crops, dunes, marsh, and Eucalyptus plantations. The interpretation was carried out using photographic properties such as color, shape, size, pattern, texture, shadows, and site (e.g., Lillesand and Kiefer 1994). We classified vegetation units or polygons with five vegetation attributes of physiognomy and species composition: (1) trees (mainly P. pinea and Quercus suber); (2) tall $(>1.5 \mathrm{~m})$ shrubs (subsequently referred to as 
TABLE 1. Landscape context and composition variables used for the spatial models.

\begin{tabular}{|c|c|c|}
\hline $\begin{array}{l}\text { Abbrevia- } \\
\text { tion }\end{array}$ & Variable & Definition \\
\hline \multicolumn{3}{|c|}{ Landscape composition variables (extracted from the fine-scale map of the structure of the vegetation) } \\
\hline MS & mean scrub + bush cover & $\begin{array}{l}\text { Mean cover of scrubs and bushes in the territory, adjusted for territory } \\
\text { area }\left(=\Sigma\left[A_{\text {patch }} \times\left(\delta_{\text {scrub }}+\delta_{\text {bush }}\right)\right] / A_{\text {territory }} ; \text { with } A_{\text {patch }}=\text { patch area; } \delta_{1}\right. \\
\quad=\text { percentage of the patch covered by layer } 1)\end{array}$ \\
\hline MB & mean bush cover & Mean cover of bushes in the territory $\left(=\Sigma\left(A_{\text {patch }} \times \delta_{\text {bush }}\right) / A_{\text {territory }}\right)$ \\
\hline MP & mean pasture coverage & Mean cover of pastures in the territory $\left(=\sum\left(A_{\text {patch }} \times \delta_{\text {pasture }}\right) / A_{\text {territory }}\right)$ \\
\hline$\% \mathrm{~S}$ & percentage of shrubland & $\begin{array}{l}\text { Percentage of the territory occupied by patches in which the sum of } \\
\text { scrub and bush cover is }>50 \%\end{array}$ \\
\hline$\% \mathrm{RF}$ & percentage of reforestations & $\begin{array}{l}\text { Percentage of the territory occupied by linear pine reforestations, } \\
\text { achieved since the } 1950 \mathrm{~s}\end{array}$ \\
\hline eSP & $\begin{array}{l}\text { edge between shrubland and pas- } \\
\text { tureland }\end{array}$ & $\begin{array}{l}\text { Linear measure, in } \mathrm{m} / \mathrm{km}^{2} \text {, of the density with respect to the territory } \\
\text { size of ecotone inside the territory between patches with bush }+ \\
\text { scrub cover }>50 \% \text { and patches with pasture cover }>50 \%\end{array}$ \\
\hline AWF & area weighted fractal dimension & $\begin{array}{l}\text { Measure of patch shape complexity, adjusted for shape size, inside the } \\
\text { territory; approaches } 1 \text { for shapes with simple perimeters and ap- } \\
\text { proaches } 2 \text { when shapes are more complex }\end{array}$ \\
\hline SDi & $\begin{array}{l}\text { Shannon landscape diversity } \\
\text { index }\end{array}$ & $\begin{array}{l}\text { Measure of relative patch diversity inside the territory; equals } 0 \text { when } \\
\text { there is only one patch in the landscape and increases as the number } \\
\text { of patch types or proportional distribution of patch types increases }\end{array}$ \\
\hline Nfo & number of patch classes & $\begin{array}{l}\text { Number of different patch types inside the territory; } 18 \text { classes were } \\
\text { created attending to layers coverage and species of the dominant } \\
\text { vegetation }\end{array}$ \\
\hline \multicolumn{3}{|c|}{ Landscape context variables (measured from land use/land cover map, and the digital geographic maps) } \\
\hline $\mathrm{XB}$ & percentage of matrix & $\begin{array}{l}\text { Percentage of the territory and a buffer area of } 500 \mathrm{~m} \text { around it, occu- } \\
\text { pied by matrix, i.e., crops, dunes, marsh, and eucalyptus plantations }\end{array}$ \\
\hline DRo & distance to paved roads & $\begin{array}{l}\text { Measured in meters from the nearest border of the territory to the near- } \\
\text { est road }\end{array}$ \\
\hline DVi & distance to village & $\begin{array}{l}\text { Measured in meters from the nearest border of the territory to the near- } \\
\text { est human settlement }\end{array}$ \\
\hline Pro & protection of the area & Indicates if the territory is inside or outside the Doñana National Park \\
\hline
\end{tabular}

bushes) of mature Mediterranean shrubland (e.g., $P$. lentiscus, M. communis) and also tall, thicket Erica spp.; (3) short ( $<1.5 \mathrm{~m}$ ) shrubs (H. halimifolium, Ulex spp., Stauracanthus genistoides, Erica spp.); (4) pastures; and (5) vegetation associated with wet soils such as reed and ferns. Each vegetation attribute in the vegetation polygons was also classified into cover intervals of $25 \%$, coded from 1 to 4 , representing the density of each vegetation layer within the polygon. Also, the dominant vegetation type (namely formation) was recorded, obtaining a total of 19 different formation types. Vegetation polygons were digitized on-screen, using ArcView GIS 3.1 (ESRI, Redlands, California, USA), by transference to an IRS-3 panchromatic satellite image of the same month of the aerial photographs. The result was a fine-scale digital map with

TABLE 2. Statistical comparisons for landscape variables between territories $(n=15)$ and random nonterritory circles $(n=15)$.

\begin{tabular}{lcrrr}
\hline \hline & & & \multicolumn{2}{c}{ Univariate tests $\dagger$} \\
\cline { 3 - 5 } Variable & Territories & Random & \multicolumn{1}{c}{$\chi^{2}$} & \multicolumn{1}{c}{$P$} \\
\hline MS & $2.52 \pm 0.19$ & $2.21 \pm 0.18$ & 3.26 & 0.07 \\
MB & $0.88 \pm 0.11$ & $0.30 \pm 0.11$ & 12.29 & $<0.01^{*}$ \\
MP & $0.63 \pm 0.08$ & $0.29 \pm 0.06$ & 8.55 & $<0.01^{*}$ \\
$\%$ S & $62.53 \pm 4.76$ & $41.13 \pm 6.83$ & 5.49 & $0.02^{*}$ \\
$\%$ RF & $1.88 \pm 1.36$ & $13.39 \pm 4.99$ & 4.29 & $0.04^{*}$ \\
eSP & $2099 \pm 354$ & $147 \pm 47$ & 21.48 & $<0.01^{*}$ \\
AWF & $1.12 \pm 0.01$ & $1.11 \pm 0.01$ & 1.53 & 0.22 \\
SDi & $1.96 \pm 0.05$ & $1.84 \pm 0.58$ & 1.30 & 0.25 \\
Nfo & $10.73 \pm 0.53$ & $10.07 \pm 0.50$ & 0.20 & 0.66 \\
XB & $17.13 \pm 3.21$ & $18.68 \pm 3.95$ & 0.03 & 0.85 \\
DRo & $5824 \pm 1640$ & $1559 \pm 363$ & 6.38 & $0.01^{*}$ \\
DVi & $6370 \pm 1452$ & $6074 \pm 861$ & 0.65 & 0.42 \\
Pro & $10 / 5$ & $5 / 10$ & 2.13 & 0.14 \\
\hline
\end{tabular}

Notes: Values are means $\pm 1 \mathrm{SE}$, except Pro, where numbers of observations inside/outside Doñana National Park are given. Asterisks indicate significant differences at $P<0.05$.

$\dagger$ All variables were tested using Kruskal-Wallis except Pro, which was tested with $\chi^{2}$ test for contingency tables. 
5425 polygons and six vegetation attributes per polygon, with a mode area of 3.4 ha. The classification accuracy for each vegetation layer was between 78.2 and $86.7 \%$.

We also used 1:100000 scale vector digital maps of roads, urban settlements, and protected areas, digitized using cartographic information dated 1996 (Instituto de Cartografía de Andalucía 1999). Roads included a national highway, national and regional roads, and local paved and unpaved ways. Only paved ways were considered, so the local ones were visited to revise the database. Urban settlements included towns and villages surrounding the National and Natural Parks with $>1000$ inhabitants.

ArcInfo 8.0 (ESRI, Redlands, California, USA) was used to calculate means and percentages of vegetation variables within territories, to identify ecotones, and to calculate their density (Table 1). Landscape indices, as well as calculations using distances, were estimated using script programs for Arc/View 3.1.

\section{Model selection method}

We based our inferences on relationships between the distribution and size of territories and landscape structure on information-theoretic methods. These methods focus on the search for a parsimonious model as the primary philosophy of statistical inference (Burnham and Anderson 1998). We first specified a set of a priori candidate models describing the breeding territory distribution on one hand, and their size on the other. Model selection would be addressed latter using a parsimony index.

For selecting predictor variables and formulating the candidate models, we considered four working hypotheses addressing the critical points of Iberian lynx breeding habitat. These were founded on a relatively wide previous knowledge of lynx ecology (Gaona et al. 1998, Fernández and Palomares 2000, Palomares 2001b, Palomares et al. 2001): (1) Iberian lynx need shrub vegetation patches to rest and breed. Also, its hunting strategy constrains it to feed among sheltering vegetation. (2) Rabbits, the main lynx prey, need pastures to feed. Also, at local scales, rabbits have been shown to reach higher densities in habitats where they have access to refuges in the vegetation. (3) More complex and heterogeneous landscapes provide better opportunities to find all the resources that Iberian lynx need, such as places to rest, breed, forage, etc. (4) Human proximity, infrastructure, and extensive forestry uses are detrimental to the species because they produce higher mortality and disturbance, and degrade the original Mediterranean ecosystems.

Fitted models (see below) were compared through the hierarchical ordering of the sets of candidate models; for this, we estimated and ranked for each model a second-order modification of Akaike's Information Criterion $\left(\mathrm{AIC}_{\mathrm{c}}\right)$ which is suitable for situations with low sample sizes in relation to the number of parameters:

$$
\mathrm{AIC}_{\mathrm{c}}=\mathrm{AIC}+\frac{2 K(K+1)}{n-K-1}
$$

where $K=$ number of estimable parameters and $n=$ sample size.

Last, model selection uncertainty was addressed by calculating weighted $\mathrm{AIC}_{\mathrm{c}}$ values for the set of candidate models (Burnham and Anderson 1998). One or a few best approximating models were selected from the first positions in the ranking.

\section{Territory distribution model}

The study domain for this model was restricted to resident habitat patches as coarsely identified in previous studies, which encompassed Mediterranean shrubland and pine formations (Palomares et al. 2000). Here, we compared the landscape characteristics of the observed territories (occurrences) with unused areas (absences; Mladenoff et al. 1995). For this, we generated a nonoccurrence sample, consisting of randomly distributed circular areas. This design was adequate because no breeding has been recorded in Doñana outside the observed territories during the long-term Iberian lynx monitoring programs described above, although the use by nonresident individuals of all the areas within the study domain has frequently been recorded. The number of generated nonterritory areas was equal to the number of territories, and their size, equal to the mean KE80 home range size for resident females. Random circle generation was performed without allowing overlapping among them or with actual territories.

We fitted 15 candidate models comparing territories with nonterritory areas, using direct logistic regression analyses in which all predictors entered the equations simultaneously (Tabachnick and Fidell 1996). Before fitting these models, we calculated a correlation matrix among all the predictor variables for territories using Spearman rank coefficients (Sokal and Rohlf 1995); candidate models containing highly correlated predictors $(r>0.6)$ were modified or eliminated from the set. Univariate statistical differences between territories and nonterritories were also tested using the Kruskal-Wallis test (Sokal and Rohlf 1995).

Once the best approximating model was selected, a model evaluation with a different data set was desirable (Guisan and Zimmermann 2000). However, the small size of the Iberian lynx population in Doñana did not allow us to use separate sets for model fitting and evaluation. Thus, we performed a best approximating model evaluation using a split-sample crossvalidation technique. The original data set was randomly divided into five partitions, each one containing three territory and three nonterritory samples. Then, four partitions were used for model fitting (prediction sample) and the fifth (crossvalidation sample) for model validation through 
the estimation of the relevant group probability for each observation. Partitions for model fitting and validation were alternated five times successively, so a different partition served each time for a new model validation. Afterwards, a new randomization was generated, and the whole process was repeated 20 times. Classification accuracy was then calculated as the mean frequency (from 0 to 1 ) of correct classifications.

All statistics were performed using the SAS version 8.01 statistical package (SAS Institute 1990). Splitsample crossvalidation was performed using a macro routine programmed in SAS.

\section{Territory size model}

We analyzed the correlation between Iberian lynx territory size and each landscape composition predictor, using the Pearson product-moment correlation. We did not find any reason to think that any of our context variables could be causing lynxes to adjust their territory sizes, so these were not used for this purpose. For the same reason, we did not include the variable Nfo (see Table 1 for definition). Multiple linear regression analyses were used to infer the relationships between landscape structure and the extent of habitat occupied by lynx territories. A set of ten candidate models similar to the one used to test territory distribution was explored to achieve the best approximating model. We employed a natural logarithm transformation of the territory area and some predictors to comply with assumptions of multiple regression analysis (Tabachnick and Fidell 1996). The amount of the variance in territory size explained by predictors in the best model was assessed with the adjusted $R^{2}$ statistic. Models were fitted using the REG procedure in SAS 8.01.

\section{Mapping habitat probabilities}

We represented probabilities of territory presence within the study area by applying the best approximating predictive model to regular packing hexagon layers; each hexagon had an area equal to the mean female KE80 home range area. Hexagons were used because they are the packing shapes best approximating circles. The detection of potential areas using this method may be influenced by the spatial arrangement of hexagons, and one single hexagon layer could misestimate territory presence probabilities in some areas (e.g., favorable areas distributed among two adjacent hexagons in a given layer might not be detected). To avoid this, we generated 20 replicated layers, which were displaced with respect to the original one in the direction of all hexagon diagonals and the major and minor axes. This displacement was performed in regular intervals, in a manner that intersecting all layers produced a new layer composed by triangular units. The intersection layer contained two attributes per triangle: one attribute summarized the mean predicted probability derived from the intersected hexagons, and the other summarized the coefficient of variation of this mean. As a result, we obtained two maps, one of mean predicted habitat probability, and another describing the uncertainty of this prediction derived from the spatial arrangement of the intersected layers. We also mapped territory size based on the best approximating model using this procedure. In this, model output was reclassified into four categories of habitat quality for reproduction in function of the predicted territory size: High (predicted size $<3 \mathrm{~km}^{2}$ ), medium (3$\left.\leq 6 \mathrm{~km}^{2}\right)$, low $\left(6-\leq 9 \mathrm{~km}^{2}\right)$, and very low $\left(>9 \mathrm{~km}^{2}\right)$.

\section{Prey abundance}

Previous studies have shown that pellet counts are reliable and accurate estimators of rabbit abundance in broad-scale surveys (Palomares 2001a). Therefore, we designed rabbit sampling based on counting rabbit pellets in random plots within the study area. We aimed to test if rabbit abundance was higher in the proximity of the patches, ecotones, roads, or other landscape elements predicting Iberian lynx distribution and/or abundance. With this objective, we performed a balanced ANOVA design, in which we stratified the sampling according to the definition of areas of influence of these landscape elements (Wilson et al. 1996). Thus, for each predictor of either territory distribution or size, we selected 50 sampling plots within and 50 plots outside the area of influence. The area of influence was defined as the area covered by the patch, ecotone, or other landscape element, including a buffer of $300 \mathrm{~m}$ beyond it. This distance was selected because a shrubland-pastureland ecotone in a smaller area in Doñana was shown to have effects on rabbit abundance within a 300-m band (Palomares et al. 2001). Also, it represents about twice the maximum axis of the mean home range for rabbits in the area (Villafuerte 1994), so our approach was, in any case, conservative.

Pellet sampling plots were set by random UTM coordinate generation within each stratum, and they were located in the field using a global positioning system (Garmin GPS III Pilot; Garmin, Olathe, Kansas, USA). In each plot, pellets were counted within two $0.5-\mathrm{m}^{2}$ circles separated by $5 \mathrm{~m}$. In order to maximize pellet counts in plots, the survey was conducted during the year 2000 from July to September, after the peak of maximum rabbit abundance and when pellet disappearance in the field is lower (Palomares 2001a).

Differences in rabbit pellet abundance within and outside areas of influence of the landscape predictors derived from Iberian lynx models were tested using procedure GLM in SAS 8.01 (SAS Institute 1990). The dependent variable was transformed using the natural logarithm to conform ANOVA assumptions.

\section{RESUlts}

\section{Landscape characterization of breeding territories}

Out of 22 Iberian lynx for which KE80 home ranges were estimated, 12 were males and 10 females. Fifteen 
TABLE 3. Summary of logistic predictive models for breeding territory distribution, and model selection estimators; $-2 \log (L)=-2 \log$-likelihood estimates; $\mathrm{AIC}_{\mathrm{c}}=$ second order Akaike's Information Criterion; $\Delta_{i}=\left(\mathrm{AIC}_{\mathrm{c}}\right)_{i}-\left(\mathrm{AIC}_{\mathrm{c}}\right)_{\min }$; Akaike $W_{i}=$ Akaike weights.

\begin{tabular}{|c|c|c|c|c|c|}
\hline Model $\uparrow$ & $-2 \log (L)$ & $\mathrm{AIC}_{\mathrm{c}}$ & $\Delta_{i}$ & Akaike $W_{i}$ & Ranking \\
\hline \multicolumn{6}{|l|}{ Null model } \\
\hline 1. Intercept only & 41.6 & 43.7 & 33.8 & $0.3 \times 10^{-9}$ & 14 \\
\hline \multicolumn{6}{|l|}{ Protective vegetation } \\
\hline 2. $\% \mathrm{~S}, \mathrm{MB}, \% \mathrm{RF}$ & 28.4 & 38.9 & 29.0 & $0.4 \times 10^{-8}$ & 9 \\
\hline 3. $\% \mathrm{~S}, \mathrm{MB}$ & 29.7 & 37.3 & 27.4 & $0.9 \times 10^{-8}$ & 8 \\
\hline 4. $\% \mathrm{~S}$ & 35.5 & 40.4 & 30.5 & $0.2 \times 10^{-8}$ & 11 \\
\hline \multicolumn{6}{|l|}{ Favorable prey habitat } \\
\hline 5. MS, MP & 24.2 & 31.8 & 21.9 & $0.1 \times 10^{-6}$ & 4 \\
\hline 6. MB, eSP & 4.9 & 12.3 & 2.4 & 0.22 & 2 \\
\hline 7. eSP & 5.0 & 9.9 & 0 & 0.77 & 1 \\
\hline 8. $\% \mathrm{P}$ & 20.2 & 25.1 & 15.2 & $0.4 \times 10^{-3}$ & 3 \\
\hline \multicolumn{6}{|l|}{ Landscape heterogeneity and complexity } \\
\hline 9. MS, SDi, AWD, NFo & 28.6 & 42.3 & 32.4 & $0.7 \times 10^{-9}$ & 13 \\
\hline 10. SDi, NFo & 39.1 & 46.7 & 36.8 & $0.8 \times 10^{-10}$ & 15 \\
\hline \multicolumn{6}{|l|}{ Human disturbance } \\
\hline 11. $\% \mathrm{~S}, \mathrm{DRo}$, Pro, XB, \%RF & 22.7 & 39.8 & 29.9 & $0.3 \times 10^{-8}$ & 10 \\
\hline 12. $\% \mathrm{~S}, \mathrm{DR}$ o & 28.7 & 36.2 & 26.3 & $0.1 \times 10^{-7}$ & 6 \\
\hline 13. XB, \%RF & 34.4 & 42.0 & 32.1 & $0.8 \times 10^{-9}$ & 12 \\
\hline \multicolumn{6}{|l|}{ Global models } \\
\hline 14. $\% \mathrm{~S}, \mathrm{MP}, \mathrm{MB}, \mathrm{AWD}, \mathrm{Dro}, \mathrm{XB}$ & 16.3 & 37.2 & 27.3 & $0.9 \times 10^{-8}$ & 7 \\
\hline 15. MS, MP, Nfo, Pro, \%RF & 17.7 & 34.8 & 24.9 & $0.3 \times 10^{-7}$ & 5 \\
\hline
\end{tabular}

$\dagger$ See Table 1 for model definitions.

breeding Iberian lynx territories were identified using nine females and six males (Fig. 1). The mean size of these territories was $5.1 \mathrm{~km}^{2}(1 \mathrm{SE}=1.07 ; n=15)$.

Univariate analyses (Table 2) showed significant differences between territories and control areas for several of the composition variables. Mean amount of ecotones between shrubland and pastureland was almost 15 times higher within territories than within random nonterritory circles, and all territories presented more than $500 \mathrm{~m} / \mathrm{km}^{2}$ of ecotone. Protective vegetation was also more abundant within territories, with mean coverage of bushes almost three times higher than in nonbreeding areas and 1.5 times more area occupied by dense shrub patches; breeding territories also contained more pastures favorable for rabbits than other landscapes. Instead, most territories did not contain recent pine reforestation, whereas they occupied a mean of $>10 \%$ of nonbreeding areas. No significant differences existed between territories and nonterritory areas for other landscape-composition indexes. Among context variables, only the distance to roads was significantly higher in territories.

Several composition variables measured within lynx territories were correlated among themselves. Strong correlations were detected between MS and \%S $(r=$ $0.93, P<0.001)$, MP and eSP $(r=0.74, P<0.001)$, $\mathrm{MP}$ and Nfo $(r=0.76, P<0.001), \% \mathrm{~S}$ and SDi $(r=$ $0.72, P<0.001)$, and DRo and DVi $(r=0.84, P<$ $0.001)$. Moderate, significant correlations were also found between MB and \% S, MB and XB, MS and SDi,
$\% \mathrm{RF}$ and SDi, eSP and SDi, and eSP and Nfo (all $r$ between 0.5 and 0.6 , all $P<0.05$ ).

\section{Breeding territory distribution model}

The differential score between the lowest $\mathrm{AIC}_{\mathrm{c}}$ and the second lower value was only 2.4. The third model in the ranking differed by $>15 \mathrm{AIC}_{\mathrm{c}}$ units from the first one, while differences with the remaining candidates were notably higher (Table 3 ). Thus, we consider only two models to be plausible as the best approximating model. These models belonged to the set of candidates designed with the hypothesis of favorable prey habitat in mind; both included as a predictor of territory presence the density of ecotones between dense shrub and dense pasture patches, with a positive regression coefficient. Models differed in the inclusion of a second variable within the one with higher $\mathrm{AIC}_{\mathrm{c}}$, the mean bush coverage within the territory (also with positive coefficient). Equations for these models are:

$$
\begin{aligned}
\operatorname{logit}(P)= & -8.02( \pm 5.2)+0.014( \pm 0.009) \mathrm{eSP} \\
\operatorname{logit}(P)= & -8.38( \pm 5.8)+0.015( \pm 0.009) \mathrm{eSP} \\
& +0.626( \pm 3.2) \mathrm{MB}
\end{aligned}
$$

where $P$ is the probability of territory occurrence; values within parentheses are standard errors.

The calculation of Akaike weights for the 15 models showed that a $99 \%$ confidence data set could be obtained with these two models, and a $77 \%$ confidence set only with the first one (Table 3 ). The large standard 
TABLE 4. Summary of multiple regression models on $\ln$ (breeding territory area), and model selection estimators; $-2 \log (L)=-2 \log$-likelihood estimates; $\mathrm{AIC}_{\mathrm{c}}=$ second order Akaike's Information Criterion; $\Delta_{i}=\left(\mathrm{AIC}_{\mathrm{c}}\right)_{i}-\left(\mathrm{AIC}_{\mathrm{c}}\right)_{\min }$; Akaike $W_{i}=$ Akaike weights.

\begin{tabular}{|c|c|c|c|c|c|}
\hline Model $\dagger$ & Adj. $R^{2}$ & $\mathrm{AIC}_{\mathrm{c}}$ & $\Delta_{i}$ & Akaike $W_{i}$ & Ranking \\
\hline \multicolumn{6}{|l|}{ Null model } \\
\hline 1. Intercept only & $\cdots$ & -10.42 & 7.9 & 0.01 & 7 \\
\hline \multicolumn{6}{|l|}{ Protective vegetation } \\
\hline 2. $\% \mathrm{~S}, \mathrm{MB}, \% \mathrm{RF}$ & 0.30 & -5.6 & 12.7 & $0.1 \times 10^{-3}$ & 9 \\
\hline 3. $\% \mathrm{~S}, \mathrm{MB}$ & 0.34 & -9.7 & 8.6 & $0.7 \times 10^{-3}$ & 8 \\
\hline 4. $\% \mathrm{~S}$ & -0.08 & -5.4 & 12.9 & $0.9 \times 10^{-4}$ & 10 \\
\hline \multicolumn{6}{|l|}{ Favorable prey habitat } \\
\hline 5. MS, MP & 0.47 & -12.9 & 5.4 & 0.03 & 4 \\
\hline 6. $\mathrm{MB}, \ln (\mathrm{eSP})$ & 0.65 & -18.3 & 0 & 0.56 & 1 \\
\hline 7. $\ln (\mathrm{eSP})$ & 0.53 & -17.1 & 1.2 & 0.31 & 2 \\
\hline 8. $\ln (\% \mathrm{P})$ & 0.38 & -13.3 & 5.0 & 0.04 & 3 \\
\hline \multicolumn{6}{|c|}{ Landscape heterogeneity and complexity } \\
\hline 9. MS, $\ln (\mathrm{Sdi}), \ln (\mathrm{AWD})$ & 0.55 & -11.7 & 6.6 & 0.02 & 6 \\
\hline 10. $\ln (\mathrm{AWD})$ & 0.31 & -11.8 & 6.5 & 0.02 & 5 \\
\hline
\end{tabular}

$\dagger$ See Table 1 for model definitions

error for the estimation of the MB parameter put additional cautions about the use of Eq. $1 \mathrm{~b}$ for inference and predictive purposes. Therefore, we selected Eq. 1a to predict distribution of breeding territories in Doñana.

To evaluate Model 1, we classified model predictions as occurrences for $P \geq 0.5$ and absences for $P<0.5$. An examination of the percentage of correct prognoses for the original data set confirmed the adequacy of this cutoff value to maximize the percentage of correct prognoses of both territory occurrences and absences. The crossvalidation test showed that the frequency (from 0 to 1 ) of misclassification accounting for all the observations in each randomization ranged from 0.3 to 0.13 ( $n=20$ repetitions). Classification accuracy for a single crossvalidation sample ranged from 0.67 to 1 , and the mean classification accuracy was $0.93 \pm 0.01$ ( $n=100$ crossvalidations). In $64 \%$ of the crossvalidation samples, all observations were correctly classified, and in $94 \%$ of them, the accuracy was higher than 0.8 . One particular lynx territory and another random nonterritory were present in $52.8 \%$ and $50 \%$ of the crossvalidation samples with some misclassification, respectively. When crossvalidated, they were misclassified in $95 \%$ and $90 \%$ of the occasions.

\section{Breeding territory size model}

Three landscape composition variables were correlated with Iberian lynx territory size: MB $(r=-0.53$, $P=0.04)$, MP $(r=-0.57, P=0.03)$, and eSP $(r=$ $-0.53, P=0.04)$. Excepting MB and eSP, the rest of the variables correlated with territory size were, in turn, correlated among themselves.

Comparisons of $\mathrm{AIC}_{\mathrm{c}}$ values among the multiple regression equations predicting territory size showed that all models differed from the lowest $\mathrm{AIC}_{\mathrm{c}}$ in fewer than 13 units (Table 4). In spite of this high prior uncertainty, weighting the $\mathrm{AIC}_{\mathrm{c}}$ scores showed that the best model absorbed $56 \%$ of Akaike weights. A $87 \%$ confidence data set can be achieved including two models. These included the same variables as the two distribution candidate models with lower $\mathrm{AIC}_{\mathrm{c}}$. The ranking, however, was different in this case, and the model including two variables showed to be the most parsimonious candidate as best approximation to predict territory size. Equations for these models are:

$$
\begin{aligned}
\ln (\mathrm{Ts})= & 20.0( \pm 1.2)-0.62( \pm 0.24) \mathrm{MB} \\
& -0.57( \pm 0.17) \ln (\mathrm{eSP}) \\
\ln (\mathrm{Ts})= & 20.6( \pm 1.5)-0.72( \pm 0.20) \ln (\mathrm{eSP})
\end{aligned}
$$

where $\mathrm{Ts}=$ territory size; values within parentheses are standard errors.

We selected Eq. 2a as the best approximating territory size model. It predicts a decreasing tendency in the size of territories with the increase of density of ecotones between shrubland and pastureland, and the mean bush coverage in the landscape.

\section{Habitat predictive mapping}

Applying the habitat model resulted in $100.5 \mathrm{~km}^{2}$ of the study area showing mean habitat probability for the

FIG. 2. Maps of predicted habitat suitability and quality for the Iberian lynx in Doñana, derived from the application of models 1 and 2 to 22 packing hexagonal grids. (A) Estimated mean probability of breeding habitat after intersecting hexagonal grids, with lynx territories outlined in black. (B) Coefficient of variation of this mean. (C) Core areas of predicted favorable habitat, derived from the overlay of maps A and B; these areas are defined as those showing a mean probability $\geq 0.5$ and a coefficient of variation $<0.75$. (D) Estimated mean habitat quality for breeding after intersecting hexagonal grids. 


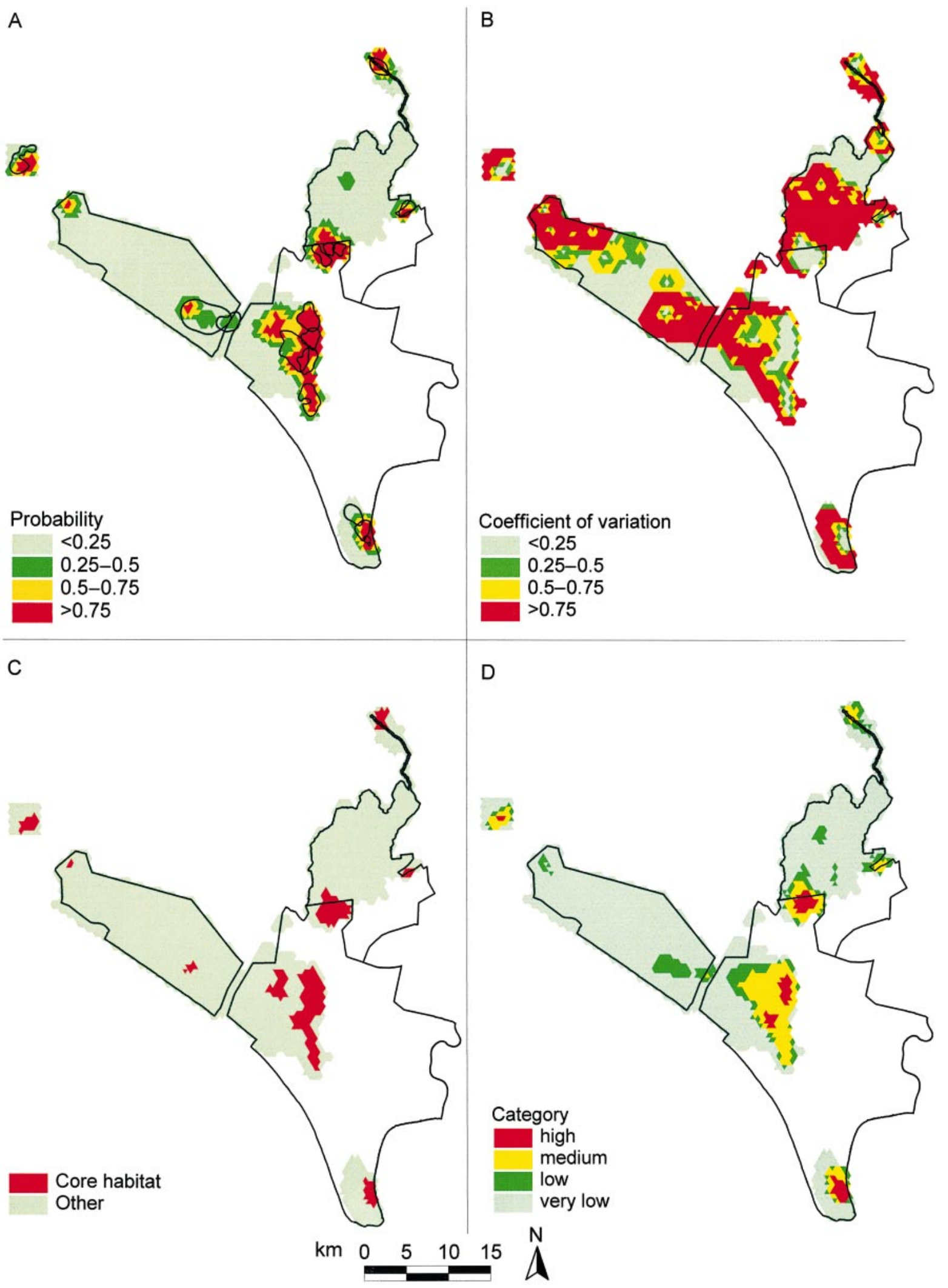




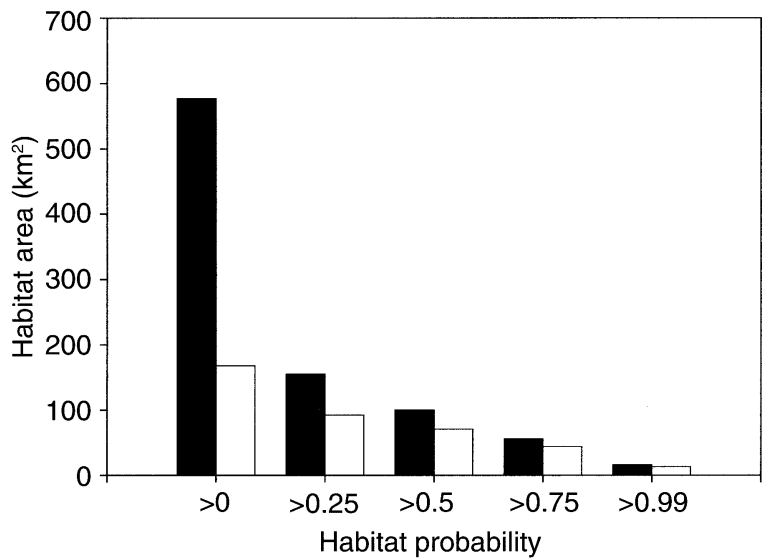

FIG. 3. Amount of favorable habitat for the Iberian lynx in Doñana, estimated using the territory distribution best approximating the model. Black bars represent accumulated areas of habitat probability higher than the specified cutoff $P$ values; white bars represent areas within the National Park, the most strictly protected area.

Iberian lynx of $P>0.5$ (Fig. 2). The distribution of most Iberian lynx territories largely coincided with mapped high-probability areas, indicating high spatial model accuracy. Of the total suitable area, only 56.2 $\mathrm{km}^{2}$ showed low spatial uncertainty in the prediction as derived from the coefficient of variation of the hexagons overly; this area represents the sum of core favorable habitats, which were highly fragmented (Fig. 2C). Most of the predicted suitable habitat occurs within the National Park (Fig. 3). Predicted habitat quality within the suitable habitat also differed; in $17 \%$ of this area quality was high, while in $29 \%$ it was low or very low (Fig. 2).

\section{Association between selected landscape features and rabbit abundance}

The abundance of ecotones between shrubland and pastureland, together with the abundance of bushes in the landscape, were the predictors selected to test rabbit associations with landscape elements predicting Iberian lynx habitat. Thus, we defined two categorical variables informing about the proximity to areas of influence of these elements. "Proximal to ecotone" took values "yes" or "no" depending on whether a given point was inside or outside a buffer area of $300 \mathrm{~m}$ around shrubland-pastureland ecotones. Taking the same values, "proximal to dense bush patch" was used to test if patches with denser bushes had effects on rabbit abundance. Thus, the rabbit survey was designed to sample four strata, each representing a particular combination of situations inside or outside buffer areas: $<300 \mathrm{~m}$ from both an ecotone and a dense bush patch boundary $(\mathrm{E}+\mathrm{B}+),<300 \mathrm{~m}$ from an ecotone and $>300 \mathrm{~m}$ from a bush patch $(\mathrm{E}+\mathrm{B}-)$, the inverse situation $(\mathrm{E}-\mathrm{B}+)$, and $>300 \mathrm{~m}$ from any of these elements $(\mathrm{E}-\mathrm{B}-)$. With this sample, we performed a GLM; the dependent variable was the number of pellets inside the plot transformed with its natural logarithm, and the fixed effects were proximal to ecotone, proximal to dense bush patch, and the interaction between these.

Mean rabbit abundance was higher within the 300$\mathrm{m}$ buffers around ecotones (mean $\pm 1 \mathrm{SE}=52 \pm 8$ pellets $\left./ \mathrm{m}^{2}\right)$ than beyond the buffers $(25 \pm 4)$. It was also higher within dense bush patch influence areas (49 $\pm 8)$ than outside them $(28 \pm 5)$. Rabbit pellets were much more abundant near both ecotones and dense bush patches $(74 \pm 13)$ than in the rest of the sampling strata (means ranged from 24 to 30; Fig. 4). The GLM showed significant effects on the abundance of rabbit pellets $\left(F_{3,196}=5.82, P<0.001\right)$. All the fixed effects analyzed were also significant: proximal to ecotone, $\left(F_{1,196}=8.14, P=0.005\right)$; proximal to dense bush $\left(F_{1,196}=4.99, P=0.027\right)$; and their interaction $\left(F_{1,196}\right.$ $=4.35, P=0.038)$.

\section{DISCUSSION}

We have presented here a hierarchical analysis of landscape factors affecting habitat for an endangered mammalian carnivore, the Iberian lynx. Our fine-scaled landscape approach provided new relevant insights for predicting distribution of breeding habitats and their relative quality in terms of breeder density. In the following sections, we discuss the contribution of this approach to the ecological understanding of the interaction between the species and the landscape, its connections with resource availability, and its consequences for regional-level population management.

\section{The fine-scale approach to spatial habitat analysis}

The distribution of Iberian lynx breeders in Doñana was closely related to landscape attributes that we called composition factors. They made reference to within-territory landscape patterns thought to be related to the availability of species-specific resources.

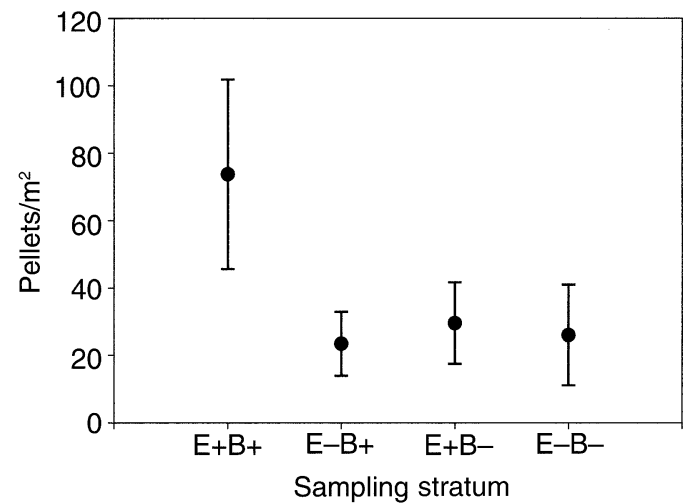

FIG. 4. Mean rabbit abundance in relation to ecotone between shrubland and pastureland, and to dense bush vegetation patches. Error bars represent $95 \%$ confidence limits for the mean. Symbols + (inside) and - (outside) indicate whether counting plots were inside or outside 300-m buffer areas around the ecotones (E) or dense bush patches (B). 
The density of ecotones between shrubland and pastureland, which takes higher values when these habitat patches are interspersed, was a robust predictor of territory occurrence.

This finding introduces a fundamental refinement over previous descriptions of Iberian lynx habitat. The species' distribution has been related to the existence of autochthonous Mediterranean shrubland (Palomares et al. 1991, Palma et al. 1999), probably as a consequence of selection for this shrubland at the homerange level (Palomares et al. 2000). However, previous research considered Mediterranean shrubland as homogeneous patches, under a landscape analysis scheme that we have defined as coarse-scaled. In our study, these shrubland areas showed dramatic differences in suitability for the Iberian lynx after examining heterogeneity at a finer scale: breeding habitat was a function of landscape variability within formerly coarsely identified habitats of scrubland and pine forests.

It seems evident that scale-dependent influences on a species' habitat may have important consequences for conservation. For example, $76 \%$ of our study area with high density of ecotones (i.e., $P>0.5$ in the predictive habitat map; Fig. 2) was occupied by breeder Iberian lynx; but $67 \%$ of the formerly defined shrubland habitat within this area did not contain any territory. Such an enhanced accuracy over earlier work has important implications for the identification of both amount of habitat available and its spatial location, since it constitutes a primary step in the design of species management strategies and assessment of population viability (e.g., Murphy and Noon 1992, Akçakaya and Atwood 1997, Cork et al. 2000). It has been argued that fine-grained data do not always improve regional-level conservation planning (Carroll et al. 1999). Instead, we have shown for the Iberian lynx that large-scale approaches may disregard landscape patterns important for regional conservation of the species' habitat.

Active restoration of breeding habitats is a major conservation concern for the Iberian lynx and many other endangered species, if high probabilities of metapopulation extinction are to be lowered (Drechsler and Wissel 1998, Gaona et al. 1998). In our specific case, providing natural Mediterranean scrubland areas with higher ecotone densities between two vegetation types can benefit the Iberian lynx population through increasing carrying capacity. The challenge of recovering the species may therefore take advantage of acting within remaining natural areas currently not favorable for breeding. Such possibility seem especially valuable for the management of endangered species confined to natural areas within intensively altered regions. In these areas, other alternatives such as restoration of agricultural, urban, hunting, or other land unfavorable for target species are often not feasible, because they conflict with other human economic and social interests.

\section{Breeding habitat quality and landscape structure}

An enormous variation existed in size of female Iberian lynx breeding territories in Doñana, ranging from $1.5 \mathrm{~km}^{2}$ to $11 \mathrm{~km}^{2}$. The analysis of this variation demonstrated that an important part could be explained by fine-scale landscape predictors (65\% of variance using the best model). Density of ecotones between shrubland and pastureland was again a good predictor (correlated negatively with size), together with mean coverage of bushes, a variable that explained the amount of tall, typically old-growth shrubs in the landscape. This outcome supports the hypothesis that lynx respond to landscape variability through adjustment of territory size, a relevant finding for several reasons.

First, the analysis of landscape patterns comes up as an attractive approach to assess within-population variations in territory size. Causes of such variation have motivated extensive research with carnivore mammals and other species, and there is large evidence on negative associations between home range sizes and abundance and quality of resources (mainly food) (e.g., Sandell 1989, Wauters and Dhondt 1992, Sherman and Eason 1998). Although it is implicit in this theory that spatial heterogeneity is important in shaping size variation, few studies on home range size have explicitly tested this (but see Kie et al. 2002). In our study, landscape variation came up as an ultimate factor influencing territory size, as abundance of some essential resources for the Iberian lynx was associated with this variation (see next section). For example, prey was more abundant in areas of ecotone between shrubland and pastureland, particularly where high bush densities also occurred. Lower density of ecotones would imply larger distances among these high prey density locations, and presumably, more space needed to satisfy female energetic requirements.

Second, the identification of landscape correlates of territory size provided a method to predict density of Iberian lynx breeders, given that both variables are strongly associated in solitary, territorial carnivores (Sandell 1989). Our inferences on habitat quality for breeding are founded on this association, linking quality to number of breeders per area unit and assuming that higher breeder density implies higher offspring productivity. This assumption is likely to be met if females with larger territories do not produce more offspring than smaller territory ones, which is not probable to occur in the Iberian lynx.

It was relevant that the best approximating model of habitat quality for breeding was similar to the territory distribution model; they differed only in one variable. Moreover, the source of uncertainty in model selection for both analyses came from the inclusion or not of one unique variable, mean landscape bush coverage. Coincidence in model predictors from both approaches increased confidence in inferences of breeding habitat for the Iberian lynx. 


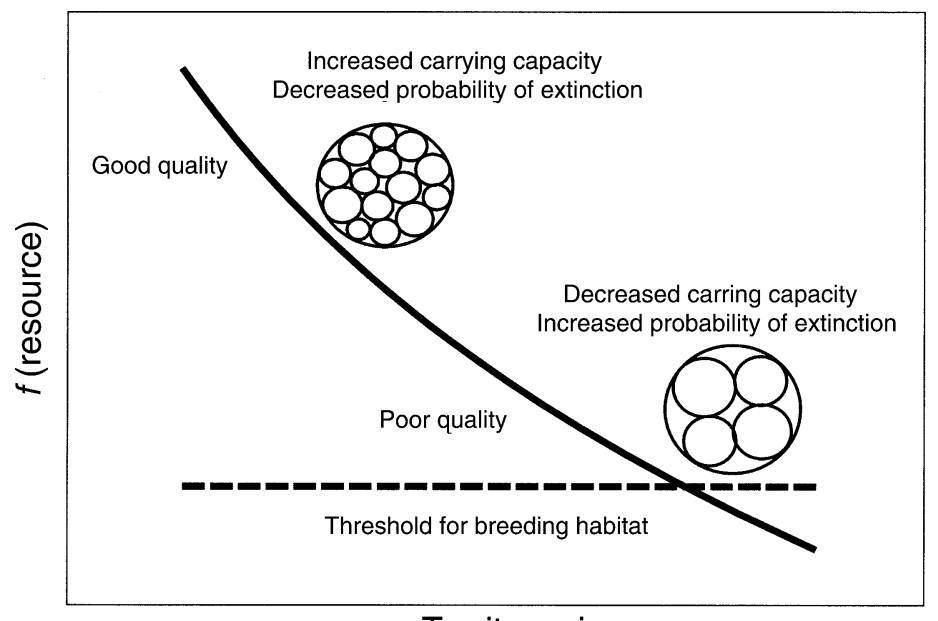

FIG. 5. Conceptualized relationship between species' breeding habitat and landscape structure. Individuals would increase their territory with the decrease of key landscape elements, which in turn may be related to the decline of quality of habitat for breeding. Breeder individuals are not found after a given threshold of abundance of such elements. As a consequence, the landscape structure generates a gradient of potential breeder density within a given area that oscillates from maximum density to the absence of breeders. Generally, higher density of breeding territories would favor population persistence through increasing the reproductive pool. Increasing territory density would also decrease extinction risks derived from edge effects, which may provoke higher mortality on reserve borders.

Territory size

From these results, both territory size and distribution models can be combined into a conceptual model of landscape structure generating a habitat-quality gradient, which decreases with the scarcity of shrublandpastureland ecotones and dense bush patches, and with a theoretical threshold of minimum ecotone density (Fig. 5). If this relationship is real, the increase in carrying capacity of the system can also be achieved reducing territory size in breeding areas through landscape management. Strategies directed to increase the density of breeders are encouraged for populations of species with large space requirements such as large mammalian carnivores. Critical reserve size and breeder female home range size are suggested to be closely related, and increasing breeder density within secure areas enhances population viability (Litvaitis et al. 1996, Woodroffe and Ginsberg 1998). Our predictive maps show that in Doñana the areas with high habitat quality for reproduction are a minority within the predicted favorable areas, even within the National Park boundaries. Thus, there is a great need to improve the carrying capacity within this Park, on which lynx population persistence is more likely to depend (Ferreras et al. 2001).

\section{Correlations between landscape structure and resource availability}

For the Iberian lynx population under study, the landscape structure related to habitat suitability and quality was also associated with primary resources for the species. Mediterranean shrubland with bushes, the abundance of which was correlated with territory size, is fundamental during breeding (Fernández and Palomares 2000). Moreover, prey benefit from proximity to shrubland-pastureland ecotones and from dense bush areas as well; areas $<300 \mathrm{~m}$ from both ecotones and dense bush patches had on average almost four times more rabbits than other areas. This seems particularly important since the Iberian lynx is strongly dependent on high rabbit abundance to survive and breed. As evidence of their importance, rabbits constitute $\sim 90 \%$ of the diet of the Iberian lynx in Doñana (Delibes 1980). A breeding territory supports at least one resident female and male and usually two or three yearlings, which translates into $\sim 1000 \mathrm{~kg}$ of rabbit biomass needed for lynx per year per territory (estimated from Aldama et al. 1991, Calzada 2000). Therefore, higher prey availability and protective habitat suggest a likely mechanism linking landscape patterns to lynx habitat selection.

Under the framework of hierarchy theory (Urban et al. 1987, King 1997 and references cited therein), the ecological causes of the landscape pattern influencing lynx territory distribution and size can be understood as an emergence, from a lower hierarchical level, of the relationship between landscapes and availability of primary resources: prey and refuge. The selection of a fine-scale of analysis in our study was evidently crucial to reveal these low-level interactions.

In conclusion, existing information on ecological requirements for relatively well-studied species such as the Iberian lynx can be combined with fine-scaled spatial analyses of landscapes to improve understanding of habitat needs. Better evidence of factors influencing habitat selection can be collected in this manner, and it provides more robust criteria to manage species habitat. A limitation of our method is the high economic and time costs of obtaining detailed information on both breeding territories and fine-grained landscape attributes; particularly for wide-ranging species like the one we are concerned with here. However, as this information is increasingly available, fine-scale habitat modeling approaches may be useful for habitat conservation and restoration, particularly in highly humanized areas where endangered species are confined to reduced extents.

ACKNOWLEDGMENTS

This study was financed by the Spanish Dirección General de Investigación, through project PB97-1163, and sponsored 
by Land Rover España. N. Fernández received a predoctoral grant from the Spanish Ministry of Science and Technology, allowing a research visit hosted by D. Mladenoff at the University of Wisconsin-Madison. Discussions with J. Calzada, P. Ferreras, E. Revilla, and A. Rodríguez greatly improved the work. We are indebted to J. M. Moreira and the Servicio de Evaluación de Recursos Naturales of Junta de Andalucía, who facilitated spatial data, aerial photographs and satellite images, and assessed during vegetation data building and GIS design. At the University of Wisconsin-Madison, T. Sickley provided guidance in GIS analysis routines. E. Nordheim assisted with some statistical analysis and Peter Crump helped with programming in SAS. Radio-tracking data on Iberian lynx were available thanks to the work developed since 1983 by numerous scientists, technicians, students, and volunteers in the carnivore ecology team at Estación Biológica de Doñana.

\section{Literature Cited}

Akçakaya, H. R., and J. L. Atwood. 1997. A habitat-based metapopulation model of the California Gnatcatcher. Conservation Biology 11:422-434.

Aldama, J. J., J. F. Beltrán, and M. Delibes. 1991. Energy expenditure and prey requirements of free-ranging Iberian lynx in southwestern Spain. Journal of Wildlife Management 55:635-641.

Boutin, S. 1990. Food supplementation experiments with terrestrial vertebrates: patterns, problems, and the future. Canadian Journal of Zoology 68:203-220.

Boyce, M. S., and L. L. McDonald. 1999. Relating populations to habitats using resource selection functions Trends in Ecology and Evolution 14:268-272.

Buckland, S. T., and D. A. Elston. 1993. Empirical models for the spatial distribution of wildlife. Journal of Applied Ecology 30:478-495.

Burnham, K. P., and D. R. Anderson. 1998. Model selection and inference. A practical information-theoretic approach. Springer-Verlag, New York, New York, USA.

Calzada, J. 2000. Impacto de depredación y selección de presa del lince ibérico y el zorro sobre el conejo. Dissertation. Universidad de León, León, Spain.

Carroll, C., R. F. Noss, and P. C. Paquet. 2001. Carnivores as focal species for conservation planning in the Rocky Mountain region. Ecological Applications 11:961-980.

Carroll, C., W. J. Zielinski, and R. F. Noss. 1999. Using presence-absence data to build and test spatial habitat models for the fisher in the Klamath region, U.S.A. Conservation Biology 13:1344-1359.

Castroviejo, J. 1993. Mapa del Parque Nacional de Doñana. Consejo Superior de Investigaciones Científicas y Agencia de Medio Ambiente de la Junta de Andalucía, Madrid, Spain.

Cork, S. J., I. D. Hume, and W. J. Foley. 2000. Improving habitat models and their utility in koala conservation. Conservation Biology 14:660-668.

Corsi, F., E. Duprè, and L. Boitani. 1999. A large-scale model of wolf distribution in Italy for conservation planning. Conservation Biology 13:150-159.

Cumming, G. S. 2000. Using between-model comparisons to fine-tune linear models of species ranges. Journal of Biogeography 27:441-455.

Delibes, M. 1980. Feeding ecology of the Spanish lynx in the Coto Doñana. Acta Theriologica 25:309-324.

Delibes, M., A. Rodríguez, and P. Ferreras. 2000. Action plan for the conservation of the Iberian lynx in Europe (Lynx pardinus). Nature and Environment 111:1-44.

Drechsler, M., and C. Wissel. 1998. Trade-offs between local and regional scale management of metapopulations. Biological Conservation 83:31-41.

Fernández, N., and F. Palomares. 2000. The selection of breeding dens by the endangered Iberian lynx (Lynx par- dinus): implications for its conservation. Biological Conservation 94:51-61.

Fernández-Delgado, C. 1997. Conservation management of an European Natural Area: Doñana National Park, Spain. Pages 458-467 in G. K. Meffe and C. R. Carroll, editors. Principles of conservation biology. Second edition. Sinauer, Sunderland, Massachusetts, USA.

Ferreras, P., J. J. Aldama, J. F. Beltrán, and M. Delibes. 1992. Rates and causes of mortality in a fragmented population of Iberian lynx Felis pardina Temminck, 1824. Biological Conservation 61:197-202.

Ferreras, P., J. F. Beltrán, J. J. Aldama, and M. Delibes. 1997. Spatial organization and land tenure system of the endangered Iberian lynx (Lynx pardinus). Journal of Zoology, London 243:163-189.

Ferreras, P., P. Gaona, F. Palomares, and M. Delibes. 2001. Restore habitat or reduce mortality? Implications from a viability analysis of the Iberian lynx. Animal Conservation 4:265-274.

Franklin, A. B., D. R. Anderson, R. J. Gutiérrez, and K. P. Burnham. 2000. Climate, habitat quality, and fitness in Northern Spotted Owl populations in northwestern California. Ecological Monographs 70:539-590.

Gaona, P., P. Ferreras, and M. Delibes. 1998. Dynamics and viability of a metapopulation of the endangered Iberian lynx (Lynx pardinus). Ecological Monographs 63:349-370.

Guisan, A., and N. E. Zimmermann. 2000. Predictive habitat distribution models in ecology. Ecological Modelling 135: 147-186.

Gustafson, E. J., and R. H. Gardner. 1996. The effect of landscape heterogeneity on the probability of patch colonization. Ecology 77:94-107.

Hall, L. S., P. R. Krausman, and M. L. Morrison. 1997. The habitat concept and a plea for standard terminology. Wildlife Society Bulletin 25:173-182.

Haslett, J. R. 1990. Geographic information systems: a new approach to habitat definition and the study of distributions. Trends in Ecology and Evolution 5:214-218.

Instituto de Cartografía de Andalucía. 1999. Mapa digital de Andalucía 1:100 000. Junta de Andalucía, Sevilla, Spain.

Johnson, D. H. 1980. The comparison of usage and availability measurements for evaluating resource preference. Ecology 61:65-71.

Kie, J. G., R. T. Bowyer, M. C. Nicholson, B. B. Boroski, and E. R. Loft. 2002. Landscape heterogeneity at differing scales: effects on spatial distribution of mule deer. Ecology 83:530-544.

King, A. W. 1997. Hierarchy theory: a guide to system structure for wildlife biologists. Pages 185-212 in J. A. Bissonette, editor. Wildlife and landscape ecology: effects of pattern and scale. Springer-Verlag, New York, New York, USA.

Lillesand, T. M., and R. W. Kiefer. 1994. Remote sensing and image interpretation. Wiley, New York, New York, USA.

Lima, S. L., and P. A. Zollner. 1996. Towards a behavioral ecology of ecological landscapes. Trends in Ecology and Evolution 11:131-135.

Litvaitis, J. A., J. F. Beltrán, M. Delibes, S. Moreno, and R. Villafuerte. 1996. Sustaining felid populations in humandominated landscapes. Journal of Wildlife Research 1:292296.

Mace, R. D., J. S. Waller, T. L. Manley, K. Ake, and W. T. Wittinger. 1999. Landscape evaluation of grizzly bear habitat in western Montana. Conservation Biology 13:367377.

MacMahon, J. A. 1997. Ecological restoration. Pages 479511 in G. K. Meffe and C. R. Carroll, editors. Principles of conservation biology. Second edition. Sinauer, Sunderland, Massachusetts, USA. 
Maehr, D. S., and J. A. Cox. 1995. Landscape features and panthers in Florida. Conservation Biology 9:1008-1019.

Massolo, A., and A. Meriggi. 1998. Factors affecting habitat occupancy by wolves in northern Apennines (northern Italy): a model of habitat suitability. Ecography 21:97-107.

Merrill, T., D. J. Mattson, R. G. Wright, and H. B. Quigley. 1999. Defining landscapes suitable for restoration of grizzly bears Ursus arctos in Idaho. Biological Conservation 87:231-248.

Mladenoff, D. J., T. A. Sickley, R. G. Haight, and A. P. Wydeven. 1995. A regional landscape analysis and prediction of favorable gray wolf habitat in the Northern Great Lakes region. Conservation Biology 9:279-294.

Mladenoff, D. J., T. A. Sickley, and A. P. Wydeven. 1999. Predicting gray wolf landscape recolonization: logistic regression models vs. new field data. Ecological Applications 9:37-44.

Moreira, J. M., and A. Fernández-Palacios. 1995. Usos y coberturas del suelo en Andalucía: seguimiento a través de imágenes de satélite. Agencia de Medio Ambiente. Junta de Andalucía, Sevilla, Spain.

Murphy, D. D., K. E. Freas, and S. B. Weiss. 1990. An environment-metapopulation approach to population viability analysis for a threatened invertebrate. Conservation Biology 4:41-51.

Murphy, D. D., and B. R. Noon. 1992. Integrating scientific methods with habitat conservation planning: reserve design for northern spotted owls. Ecological Applications 2:3-17.

Myers, N. 1997. Global biodiversity II: losses and threats. Pages 123-158 in G. K. Meffe and C. R. Carroll, editors. Principles of conservation biology. Second edition. Sinauer, Sunderland, Massachusetts, USA.

Newton, I. 1998. Population limitation in birds. Academic Press, San Diego, California, USA.

Noss, R. F., H. B. Quigley, M. G. Hornocker, T. Merrill, and P. C. Paquet. 1996. Conservation biology and carnivore conservation in the Rocky Mountains. Conservation Biology 10:949-963.

Nowell, K., and P. Jackson, editors. 1996. Wild cats. Status, survey and conservation action plan. IUCN, Gland, Switzerland.

Palma, L., P. Beja, and M. Rodrigues. 1999. The use of sighting data to analyse Iberian lynx habitat and distribution. Journal of Applied Ecology 36:812-824.

Palomares, F. 2001a. Comparison of 3 methods to estimate rabbit abundance in a Mediterranean environment. Wildlife Society Bulletin 29:578-585.

Palomares, F. 2001b. Vegetation structure and prey abundance requirements of the Iberian lynx: implications for the design of reserves and corridors. Journal of Applied Ecology 38:9-18.

Palomares, F., M. Delibes, P. Ferreras, J. M. Fedriani, J. Calzada, and E. Revilla. 2000. Iberian lynx in a fragmented landscape: predispersal, dispersal, and postdispersal habitats. Conservation Biology 14:809-818.

Palomares, F., M. Delibes, E. Revilla, J. Calzada, and J. M. Fedriani. 2001. Spatial ecology of Iberian lynx and abundance of European rabbits in southwestern Spain. Wildlife Monographs 148:1-36.

Palomares, F., A. Rodriguez, R. Laffite, and M. Delibes. 1991. The status and distribution of the Iberian lynx Felis pardina (Temminck) in Coto Doñana area, SW Spain. Biological Conservation 57:159-169.

Pearson, S. M., M. G. Turner, and J. B. Drake. 1999. Landscape change and habitat availability in the southern Ap- palachian highlands and Olympic peninsula. Ecological Applications 9:1288-1304.

Pickett, S. T. A., and M. L. Cadenasso. 1995. Landscape ecology: spatial heterogeneity in ecological systems. Science 269:331-334.

Rodríguez, A., and M. Delibes. 1992. Current range and status of the Iberian lynx Felis pardina Temminck 1824 in Spain. Biological Conservation 61:189-196.

Sandell, M. 1989. The mating tactics and spacing patterns of solitary carnivores. Pages 164-182 in J. L. Gittleman, editor. Carnivore behavior, ecology and evolution. Cornell University Press, Ithaca, New York, USA.

SAS Institute. 1990. SAS/STAT User's Guide, Version 6. SAS Institute Inc., Cary, North Carolina, USA.

Schadt, S., E. Revilla, T. Wiegand, F. Knauer, P. Kaczensky, U. Breitenmoser, L. Bufka, J. Cerveny, P. Koubek, T. Huber, C. Stanisa, and L. Trepl. 2002. Assessing the suitability of central European landscapes for the reintroduction of Eurasian lynx. Journal of Applied Ecology 39:189-203.

Seaman, D. E., and R. A. Powell. 1996. An evaluation of the accuracy of Kernel density estimators for home range analysis. Ecology 77:2075-2085.

Sherman, P. T., and P. K. Eason. 1998. Size determinants in territories with inflexible boundaries: manipulation experiments on white-winged trumpeters' territories. Ecology 79:1147-1159.

Sokal, R. S., and F. J. Rohlf. 1995. Biometry. The principles and practice of statistics in biological research. Freeman, New York, New York, USA.

Southwood, T. R. E. 1977. Habitat, the templet for ecological strategies? Journal of Animal Ecology 46:337-365.

Tabachnick, B., and L. S. Fidell. 1996. Using multivariate statistics. Harper Collins, New York, New York, USA.

Turner, M. G., R. H. Gardner, and R. V. O’Neill. 2001. Landscape ecology in theory and practice. Springer-Verlag, New York, New York, USA.

Tyre, A. J., H. P. Possingham, and D. B. Lindenmayer. 2001. Inferring process from pattern: can territory occupancy provide information about life history parameters? Ecological Applications 11:1722-1737.

Urban, D. L., R. V. O’Neill, and H. H. Shugart, Jr. 1987. A hierarchical perspective can help scientists understand spatial patterns. BioScience 37:119-127.

Villafuerte, R. 1994. Riesgo de predación y estrategias defensivas del conejo, Oryctolagus cuniculus, en el Parque Nacional de Doñana. Dissertation. Universidad de Córdoba, Córdoba, Spain.

Wauters, L., and A. A. Dhondt. 1992. Spacing behaviour of red squirrels, Sciurus vulgaris: variation between habitats and the sexes. Animal Behaviour 43:297-311.

Wiens, J. A., N. C. Stenseth, B. Van Horne, and R. A. Ims. 1993. Ecological mechanisms and landscape ecology. Oikos 66:369-380.

Wikramanayake, E. D., E. Dinerstein, J. G. Robinson, U. Karanth, A. Rabinowitz, D. Olson, T. Mathew, P. Hedao, M. Conner, G. Hemley, and D. Bolze. 1998. An ecologybased method for defining priorities for large mammal conservation: the tiger as case study. Conservation Biology 12:865-878.

Wilson, D. E., F. R. Cole, J. D. Nichols, R. Rudran, and M. S. Foster, editors. 1996. Measuring and monitoring biological diversity. Standard methods for mammals. Smithsonian Institution Press, Washington, D.C., USA.

Woodroffe, R., and J. R. Ginsberg. 1998. Edge effects and the extinction of populations inside protected areas. Science 280:2126-2128. 